\title{
Neoliberalising education: new geographies of private tuition, class privilege and minority ethnic advancement
}

\author{
Professor Sarah L. Holloway and Dr Philip Kirby
}

Paper accepted for publication in Antipode

\begin{abstract}
Geographic research on neoliberalism has explored the restructuring of educational landscapes wrought through marketisation of preschool, school and higher-education provision and considered the responsibilisation of parents and children for educational outcomes. This study develops understanding of the contingent emergence of neoliberal educational reform, and its progressive and regressive impacts, through an examination of the burgeoning private tuition market in England and Wales. The paper outlines the contours of the previously hidden supplementary education industry, demonstrating that it reinforces regional and classed inequalities, while opening possibilities for ethnic minority advancement. Conceptually, the paper advances debate about socio-spatial specificity in neoliberal change, showing that the intersection of policy, free markets and consumer behaviour reshapes the educational landscape in ways that extend beyond state intention and control. Through these processes, contingent market forms are produced that offer social mobility for some, but ensure the social reproduction of enduring regimes of power.
\end{abstract}

\section{Introduction}

Private tuition has existed in Britain for centuries. In its traditional form, it has been a precursor and alternative to schooling for children from wealthier families (Ireson \& Rushforth 2011). During the eighteenth and early nineteenth centuries, the libraries of aristocratic homes often rivalled those of formal schools and colleges, providing the resources upon which such tuition was based. Tutors were frequently graduates or dons of Oxford or Cambridge universities. Estimates suggest that as many as one third of boys in the gentry were educated at home, either prior to attending school or as a substitute for schooling (Lawson \& Silver 2007). The expansion of schooling in the latter half of the 19th century saw private tuition's role as an independent mode of education diminish. By the post-World War II period, even the British monarchy embraced schooling - albeit private - in preference to individual domestic instruction (Gordon \& Lawton 1999).

This apparent story of decline, however, has a twist in its tail. Although private tuition in Britain is now rarely an alternative to schooling for the upper classes, its market as a supplement to mainstream education has burgeoned in recent years. In this new guise, the supplementary education sector provides part-time, out-of-school tuition that is designed to enhance learning of the formal school curriculum. Notwithstanding difficulties in measurement, it is widely considered to 
have a positive effect on pupils' attainment (EEF 2018). On the international stage, late twentiethcentury England and Wales had low levels of such services (Song et al 2013), but the first decades of this century saw strong growth in market-based tuition in academic subjects (Pearce et al 2018). Following its expansion, conservative estimates suggest the market is now worth up to $£ 2$ billion per year (Kirby 2016), and the sector has been hailed as "that rare thing: a booming British industry" (Cohen 2013: 1).

This paper considers what the resurgence and reformation of a service associated with historic class privilege means for the social reproduction of in/equality and the possibilities for social mobility in contemporary England and Wales. It begins by setting the metamorphosis of private tuition in the context of the rise of neoliberal logics which frame education as a vital element for success in global knowledge economies. This neoliberalisation has prompted both marketisation of education services and the responsibilisation of families for children's educational outcomes. The central section of the paper considers the implications of this for private tuition, providing a four-fold analysis of the market in England and Wales.

First, it traces the contours of private tuition market growth: this is a crucial step for an industry which operates outside of state regulation and remains "one of the least understood education phenomena of the contemporary era" (Bray 2017: 486). Deploying quantitative data sourced through collaboration with a third-sector organisation, the paper provides a rigorous statistical account of private tuition's growth and highlights geographical variations in the market's extent and delivery. Second, it considers the new class politics of tuition as supplementary education, demonstrating that a social gradient in usage cements social inequality, even as its (tactical) usage by low-income families presents limited opportunities for social mobility. Third, the paper reveals that the resurgence of the private tuition market cannot be understood solely through the lens of class politics. Proportionally greater use of private tuition by Black, Asian and Minority Ethnic (BAME) than White families offers positive scope for minority ethnic advancement through practices that address historical inequalities in state education. Finally, the paper draws these regional, classed and racialised practices together, establishing that all are statistically important in shaping usage, but emphasising that it is through their intersection that new configurations of spatialised, classed and racialised dis/advantage are formed.

In conclusion, the paper reflects on the insights produced by this focused analysis of the geographical specificities, inconsistencies and ironies in the neoliberal education landscape. It argues that geographical analyses of neoliberal educational change must be broadened to include the sizable private tuition market that has a socio-spatially-differentiated impact on social reproduction. Conceptually, attention to this market advances understanding of the unruly emergence of neoliberal logics, stressing not only the need to explore spatial diversity in neoliberal policy, but also crucially the ways that government policy can produce market responses, from both business and consumers, that exceed state intention and control. In so doing, it accentuates the imperative for researchers to avoid framing neoliberal transformations as inherently unjust, and 
instead examine a posteriori its potential to produce progressive, as well as regressive, social change.

\section{Neoliberalisation and the Rise of Supplementary Education}

The twenty-first century renaissance of private tuition has taken place in the context of the intense neoliberalisation of education. This period has seen a convergence in policy discourses across advanced economies in which education is heralded as crucial to national and individual success. Economically, education is represented as a national investment for the future, producing a skilled workforce that will safeguard a country's competitiveness in global knowledge economies.

Politically, it is seen to aid social cohesion and reduce future state costs by giving individuals the skills to confront the challenges of the post-industrial labour market (Cheng 2015; Peters 2012). Focusing on the instrumental rather than intrinsic value of learning (Vingaard Johansen et al. 2017), these neoliberal policy discourses frame education as a sphere through which competitive market advantage can be won, and social inclusion concurrently secured through the responsibilisation of individuals (Raco 2009; Snee and Devine 2018). In the UK, these ideas were deployed to justify the roll-out neoliberal policy of the 1997 centre-left Labour Government, which invested heavily in education (DfE 1997). Almost twenty years later, discursive continuity is apparent in the policy pronouncements of the right-wing Conservative Government, despite their real-terms cuts to school funding: "The better educated our society, the fairer, more cohesive, productive and innovative it can be. This is vital to Britain's position in the 21st century. Our education system must compete with those around the world" (DfE 2016, p. 5).

Education's elevated importance on the political agenda of diverse neoliberal states has prompted a surge of geographical research, which traces how this is restructuring education systems (Cheng 2015; Mitchell 2018; Nguyen et al 2018). This research combines recognition that there is increasing homogeneity in educational discourse across the Global North with appreciation that researchers should attend to 'actually existing neoliberalism' (Brenner and Theordore 2002, p. 353), as socio-spatial specificity is crucial in how neoliberal education policies emerge in practice (Brooks et al 2012; Papanastasiou 2017). Marketisation emerges from this work as a crucial tool through which neoliberal states are restructuring education for preschool, school-aged and highereducation students (Cohen and Lizotte 2015; Gallagher 2018; Hall 2015). In compulsory education in England, this drive has not only been wrought through parental choice in a context of increased school diversity (Whitty \& Wisby, 2016; Millar, 2018), but also through changes to the curriculum, assessment and monitoring practices. Notably, the introduction of a standardised national curriculum (1988) and school league tables (1992) saw the creation of an "A-to-C economy" through which individual and school efforts to ensure pupils pass high-stakes examinations were codified, monitored and disciplined (Gillborn \& Youdell 2000). Today, pupils face an increasingly academized primary curriculum, and more stringent exams at 16 and 18, while yearly measures of progress stimulate internal market competition within schools, just as summative measures of attainment at 11, 16 and 18 discipline schools within the broader market place (Pratt 2016). 
The neoliberal discourses that underpinned these changes promised a rise in educational standards, and in social cohesion. However, the dream of equality has not been delivered as state education continues to favour wealthier social groups. School choice, for example, favours those who can afford increased house prices proximate to academically high-performing schools, and those with the cultural and economic capital to choose out-of-catchment schools (Gamsu 2018; Orford 2018; Yoon et al. 2018). Transition to secondary school (at age 11) remains a significant moment of social sorting, with educational markets particularly fraught in areas of gentrification (Butler et al. 2013; Farrales 2017; Frank and Weck 2018). These differences in access are vital: they not only reflect inequalities in society, but also play a crucial role in its social reproduction, as some gain greater access than others to educational qualifications. These educational credentials are an institutionalised form of cultural capital that have significant implications for one's life chances (Bourdieu, 2008).

Parents and young people often respond to this discursive climate by largely accepting the neoliberal social imaginary that social mobility is possible for those who work hard (Snee and Devine 2018), internalising responsibility for educational achievement (Olmedo \& Wilkins, 2016; Doherty \& Dooley 2018). This individualisation of responsibility sits well within middle-class cultures of "intensive mothering" (Hays 1996: 6) and "concerted cultivation" (Lareau 2002: 748) that promote 'optimum' child development through concentrated attention on children's needs. In England, these cultures were co-opted by consecutive Labour and Conservative-led Coalition Governments that seamlessly combined the proposition that the education system must be globally competitive with the contradictory notion that high-quality parent-child interactions, not school quality, is the most important influence on children's educational achievement (Gillies, 2012; Richter and Andresen 2012). The result is that parents are not only expected to act as informed consumers and pursue competitive advantage for their children through the school market place, they are also under increasing pressure to be personally involved with their children's learning (Holloway \& Pimlott-Wilson 2013; Olmedo \& Wilkins, 2016). Research with young people demonstrates that they too are commonly "pulled into" dominant regimes which individualise their responsibility to pass exams and fashion a successful future for themselves (Cheng 2015: 1090; Pimlott-Wilson 2017; Snee and Devine 2018).

What is missing from this geographical research into neoliberal educational landscapes is any analysis of the burgeoning supplementary education industry. In England and Wales, supplementary education is dominated by the parental purchase of private tuition: academic sessions that are designed to improve formal academic attainment, but which are delivered outside of, and often without the specific knowledge of, schools (Ireson \& Rushforth 2011). Omission of this market from the research agenda is surprising because geographers have explored the links between the neoliberalisation of schooling and informal or alternative forms of education (Mills \& Kraftl 2014; Pimlott-Wilson and Coates 2019). However, there has been silence about the ways a differentiated school market, and the responsibilisation of families for educational attainment, 
connects with the resurgence of the private tuition industry. Although school education and private tuition remain distinct, the interlinkages between them are manifold: rising demand for tuition partly reflects the growth of test culture in schools; pupils frequently move between both forms of provision; and crossover in (tutor) employment between the sectors is common (e.g. $43 \%$ of stateschool teachers in England have undertaken paid tutoring at some point [Kirby 2016]).

Although overlooked by geographers, supplementary education has received considerable attention in international and comparative studies of education (Aurini, 2013). In these, it is often referred to metaphorically as shadow education - given that it mirrors the formal school system, but is shaded from view - although the term 'supplementary education' is increasingly used (Bray 2017). Globally, shadow or supplementary education is widespread in East Asia, where Confucian values and high-stakes examinations, amongst other factors, have been found to stimulate demand (Jheng 2015). It has also grown rapidly in post-Soviet states in response to the underfunding of state education (Silova 2010). England and Wales, like much of Western Europe, North America and Australasia had relatively low rates of tutoring at the turn of the twenty-first century, but this is now changing (Bray \& Kobakhidze 2014). This matters because the consensus of international studies shows that, while it is difficult to measure the effectiveness of tuition exactly, it is considered overall to raise attainment (EEF 2018). Questions about who benefits from a service that has the power to shape social reproduction require urgent geographical attention.

The aims of this paper are to focus attention on the resurgence of private tuition as a form of supplementary education and to consider what this market means for social reproduction. Its approach is guided by two specific insights from the literature. The first is that broad-brush accounts of neoliberalism are insufficient, and that textured accounts of how such policy shapes educational practice in specific time-spaces are required (Brooks et al. 2012; Papanastasiou 2017). The paper therefore provides a first, textured mapping of the rise and extent of private tuition in England and Wales: this is vital as it should not be assumed that private tuition markets are the same everywhere, nor indeed that they are evenly spread. The second is that the political ramifications of neoliberal educational landscapes should not be judged in uniform, a priori ways. Although the neoliberal promise of social cohesion through education is currently belied through Conservative funding cuts, one should not assume that all practices advanced through neoliberal logics are regressive; market-based reforms can (sometimes) be implicated in progressive outcomes (Gallagher 2018; Mills \& McCreary 2013). Consequently, the paper explores exactly who does and does not benefit from the marketisation of this rapidly growing form of education, facilitating a more nuanced account of the ways that market-based services reinforce and disrupt social reproduction.

\section{Methodology}

The challenges of researching an industry which exists in the shadows are well-documented (Bray 2010): industry actors understand their own market objectives and parents recognise the financial 
burden of tuition, but only by working with children is it possible to see exactly who has access to this service. To produce a rigorous insight into the contours of the market, this study draws upon large-scale, representative surveys of children aged 11-16 in English and Welsh state schools, conducted for the Sutton Trust by Ipsos MORI. For the surveys, pupils were selected from a random sample of maintained schools (listed on the government Edubase database), with pupil data weighted by school year, gender and region to align with the national profile of school children. These surveys have been conducted on multiple occasions, and two years are considered here to allow time comparison: 2005 ( $n=2,709)$, the first year of the survey; and 2016 $(n=2,555)$, the most recent year available. Fieldwork was undertaken from January 10-March 11 2005 and from January 18-April 26 2016. Questionnaires were completed by pupils under the supervision of an Ipsos MORI interviewer.

Access to this rich data set is a beneficial outcome of collaboration between academic and third-sector organisations, with one author (Kirby) involved in determining the 2016 survey questions whilst employed by the Sutton Trust. Founded in 1997, the Trust works to "improve social mobility in the UK through evidence-based programmes, research and policy advocacy" (Sutton Trust 2018: no pagination). The survey considered here captures pupils' access to private tuition (over their school career and past calendar year); the demographic characteristics of young people using tutors (including class, gender, ethnicity, location); the purpose, topic and utility of tuition; and its organisation (e.g. hours, location, pressure). Class is measured through the Family Affluence Scale (FAS) II: a widely-used tripartite classification, which provides children with a family affluence score based on a series of questions about material possessions and lifestyle. Ethnicity data is aligned with the major ethnic groups (White, Black, Asian, Mixed, Other) collected by the Government's Department for Education, though on occasions in this paper these are reduced to binary categories (Black, Asian and Minority Ethnic [BAME], and White) to allow for certain statistical tests.

These two sets of survey data have been analysed using SPSS. The data were coded to exclude missing data, removing cases where questions applied to children but were not answered. They were then subject to chi-square analysis to highlight variations in access to, and use of, tuition between 2005 and 2016, for children with different demographic characteristics. All significance tests have been calculated at the $5 \%$ level; the chi-square value and probability are reported in footnotes for rigour. Subsequently, forced-entry binary logistic regression was employed to test the ideas seen in the wider literature that region, class and ethnicity all shape tuition usage. This test requires a comparator group: this was defined as wealthy, Asian Londoners, as these are the characteristics associated with highest tuition use. Results reported include both the chi-square value and probability for each stage of the model, and the odds ratios associated with each of the categorical groupings (with their upper and lower confidence intervals).

The use of quantitative methods in this study has both broad-scale benefits and some limitations. In researching an educational practice that exists outside of state regulation, and 
remains under-researched (Bray, 2017), this quantitative approach offers a vital step forward in rigorously mapping the contours of the tuition market in England and Wales and authoritatively tracing social variations in its use. The use of chi-square analysis, alongside binary logistic regression, allows us to understand who is benefitting from this service and where, and how significant place and various social characteristics are in shaping patterns of usage. Nevertheless, all methods have limitations. This account is constrained by the questions asked originally in 2005 and the fact that it cannot follow research threads by delving deeper (qualitatively) into individual motivations. Equally, the complexity of concepts such as 'wealth' and 'ethnicity' are only partly captured by constructs like FAS and BAME. Nevertheless, statistical research plays a vital role in framing previously hidden educational practices. Grasping the shape and size of a phenomenon is crucial in understanding its consequences for society.

\section{National, regional and local geographies of private tuition}

Globally, the present scale and composition of supplementary education is historically unique, with the industry employing and catering for millions of tutors and students (Aurini et al 2013; Bray 2017). In England and Wales, the tuition market is burgeoning: in 2005, $18.3 \%$ of stateeducated pupils aged 11-16 received private tuition at some point in their academic career, but by 2016 this figure had risen to $26.2 \% .^{1}$ The market is highly instrumental, focusing on performance within, and access to, schooling: nearly half (47.9\%) of 2016 respondents received tuition to assist with general school work; over a third (39.1\%) to support specific GCSE examinations (high-stake examinations taken at age 16 before pupils split into academic or vocation-orientated pathways); and nearly a fifth (18.8\%) to help access selective schooling. ${ }^{2}$ This instrumentality reflects both the importance of educational attainment in current labour markets and the responsibilisation of parents and children for academic outcomes (Pimlott-Wilson 2017; Snee and Devine 2018). Indeed, this strategic use of tuition is evident in the diversity of subjects studied: Maths (69.5\%) and English (48.9\%) are most popular, where pass marks have a vital role in shaping transitions into post-16 education and the labour market (Higton et al 2017).

By contrast, the acquisition of musical (21.6\%) and language (9.6\%) skills is less common, despite their importance in the creation of what has been called the middle-class "renaissance child" (Vincent \& Ball 2007: 1071). Here, the institutionalisation of this embodied cultural capital (Bourdieu 2008) may be less important as it is not crucial to future academic and work success, albeit these skills have been shown to make particular students appear appropriate for recruitment to certain elite professions (Rivera 2015). Across the board, the competitive nature of private tuition is evident in that three quarters of children already thought they were doing well in that subject when they started using a tutor, suggesting that for these pupils (93\% of whom found it helpful) tuition is about academic excellence.

At the regional level, the tuition industry is characterised by a distinctive three-fold geography (see Table 1). ${ }^{3456}$ London sits apart from the rest of the nation with highest levels of 
usage. In 2016, 43.8\% of London pupils aged 11-16 had received private tuition at some point, a figure significantly above that for England and Wales as a whole (26.2\%). This strength in the capital's private tuition market is an important trend (Baker et al 2014; Tanner et al 2009), and this analysis demonstrates that it had already emerged when data collection began in 2005 (see Table 1). Private tuition is often referred to metaphorically as 'shadow education' in the international literature, emphasising the ways in which the sector mirrors the shape of mainstream schooling (Bray 2017). This is extremely apt in the case of London. State education in the capital receives preferential funding compared with the regions (Clifton et al., 2016), but population growth and change means the system is highly competitive, both in terms of access to preferred schools and attainment (Butler et al. 2013; Gamsu 2018). This pressure cooker atmosphere in London's stateeducation market goes hand-in-hand with raised levels of tuition usage.

A second set of regions, spanning the South, East, Midlands, Wales and part of the North of England, sit near the national average of just over one quarter of pupils receiving private tuition. The 'average' nature of these regions, however, obscures some significant ways in which here too spatial variability in the national school system shapes tuition use. In this case, the proportion of children who report having used tuition to prepare for a school entrance exam varies significantly across England and Wales. The tuition used by these state-educated pupils is most likely to facilitate access to grammar schools. Most state schools have a comprehensive intake that spans the ability spectrum, but government-funded grammar schools can select pupils by ability and they are consequently associated with high attainment. The pervasiveness of these schools, which tend to be more popular amongst right-wing politicians, varies between regions, reflecting the choices made by the local authority. Tuition to facilitate selective-school entry is highest in the South East (38.4\%), the English region with (by far) the highest proportion of state-educated secondary pupils in grammar schools (12\%); it is lowest in the East Midlands (5.8\%), where only one county (Lincolnshire) has grammar schools, and in Wales (5.6\%), which has none (Bolton 2017).

The final two regions - Yorkshire and Humberside, and the North West, which are relatively less prosperous - have a significantly lower proportion of pupils receiving tuition than the national average, a fact which reinforces the broader geography of North-South socio-economic divides in England (Cribb et al 2017). Perversely, these regions also suffer from reduced state funding for education, as London secondary schools receive $£ 1,300$ more per pupil than the $£ 5,700$ per head given to northern secondary schools. Much of this difference is accounted for by the higher cost of living in London; however, historical decisions have also produced unwarranted differences. The delayed new national funding formula is designed to address these, a process which will increase the relative funding of schools in economically-deprived parts of northern cities (Clifton et al., 2016). Today, this means that pupils in these northern regions are not only more likely attend schools that struggle to recruit and retain leaders and teachers (Clifton et al., 2016), they are less likely to have help in the form of private tuition. 
At the local level, the everyday spatiality of the industry is equally noteworthy. In the international literature the term 'shadow education' is considered apt to describe private tuition because, compared to state schooling, the private tuition industry is opaque (Bray 2017). In England and Wales, the 'hidden' nature of the industry is enhanced by its domestication, with its primary location in private spaces meaning that sectoral strength is easily obscured. Two-thirds of private tuition sessions take place in a home environment (43.5\% tutee's home; $23.4 \%$ tutor's home), largely out of public view. Only $21.4 \%$ of sessions are carried out in non-residential buildings where other children are being tutored simultaneously. These may be permanent tuition centres which are visible on the high street, offering individual and/or group tuition (Tanner et al 2009), or franchises that rent less-noticeable space in community buildings to deliver group tuition. This is a significant finding internationally as this domestic spatiality in England and Wales directly contrasts with the market formation in East Asia, where usage is more widespread. There, although private tuition attracts less academic attention than its mainstream equivalent, the industry is highly visible in the urban landscape. Provision in commercial premises that cluster near major transport hubs or schools is common, and large groups sessions, frequently taught by "superstar" tutors, are the norm (Kirby 2016). While private tuition is flourishing around the globe (Bray \& Kobakhidze 2014), this growth materialises in locally-specific formations.

\section{Educational transitions and the contested reproduction of class advantage}

In the English and Welsh context, an industry once devoted to the education of the rich now has the potential to reinforce or reframe the social reproduction of class. This research demonstrates that there are significant class differences in access to private tuition: $31.2 \%$ from highly-affluent backgrounds have had tuition, compared with $20.6 \%$ from medium-affluence families and $15.5 \%$ from low-affluence households. ${ }^{7}$ These findings are not surprising, falling in line with previous policy reports into socially-differentiated access to private tuition (Chanfreau et al. 2015; Francis \& Hutchings 2013), but they are nevertheless important. The role of parental affluence in facilitating children's access to private tuition - and its concomitant economic, cultural and social capitals raises urgent questions about class reproduction and social mobility (Craig et al 2014). Previous research demonstrates the importance of middle-class economic power in accessing high quality education through the purchase of homes proximate to high-attainment schools (Hamnett \& Butler 2011; Orford 2018), but to this we must now add the capacity to purchase private tuition. These investments matter because structural changes in the education sector (e.g. competition for "good" university places) and upskilling in the labour market (e.g. graduates now constitute $42 \%$ of the working-age population [ONS 2017]) mean that the acquisition of educational credentials is vital to, if not solely sufficient for, future success.

It is important, however, to consider how neoliberal policy may open, as well as close down, possibilities for progressive social outcomes (Gallagher 2018; Mills \& McCreary 2013). The more targeted use of private tuition by low-income families than their wealthier peers suggests that an industry which is largely regressive in class terms might still pave pathways to social mobility for 
some. In this respect, it is notable that low-FAS families prioritise examination performance, with $70.0 \%$ reporting using private tuition to support specific GCSEs which are crucial to pupils' post-16 pathways (cf. 35.9\% medium-FAS; 38\% high-FAS). ${ }^{8}$ As such, poorer families concentrate their more limited economic resources on the acquisition of educational credentials, an institutionalised form of cultural capital (Bourdieu 2008). Moreover, low-FAS families must also prioritise tuition recipients: low-FAS children are more likely to receive tuition when their academic performance is either much better or worse than the perceived norm, whereas middle and high-FAS pupils use it more evenly across the attainment spectrum ${ }^{9}$. This targeting does not overcome the broadly regressive nature of tuition usage in terms of class, but it does offer the possibility of social mobility for a limited few.

However, a second cluster of findings indicate that low-FAS pupils are in receipt of poorer quality tuition. Significant difference in the length of tuition sessions is an important indicator of this. ${ }^{10}$ The majority (53.8\%) of low-FAS pupils' tuition lasts over one hour, a common practice in group tuition; however, this is only true for $26.5 \%$ of medium-FAS and $20.3 \%$ of high-FAS, pupils, whose modal 1-hour sessions are common in individual tuition. Moreover, the greater proportions of low-FAS pupils (41.7\%) who receive tuition in a public rather than domestic building (cf. $28.8 \%$ medium-FAS and $21.9 \%$ high-FAS pupils) ${ }^{11}$ reinforces the point that poorer pupils are more likely to receive group tuition than their more privileged counterparts. Thus, wealthier families are not only more likely to use tuition than their less privileged counterparts, they are also more likely to have access to better tuition, as more expensive one-to-one tuition is normally considered more effective than group instruction in the UK (Ireson 2004; but see below). Indeed, significant differences in children's own perceptions of the helpfulness of tuition reinforce this conclusion. ${ }^{12}$ Only $80.0 \%$ of low-FAS pupils found tuition helpful, compared to $92.6 \%$ and $93.9 \%$ of their medium and high-FAS counterparts, respectively. In sum, these findings demonstrate that parents are the economic bedrock of the private tuition industry and that, notwithstanding the enterprising efforts of some low-income families, parental class remains crucial in shaping children's access to, and experiences of, supplementary education.

\section{Educational access and a challenge to historic white privilege}

Although the current distribution of private tuition reinforces existing geographical and class privilege, the opposite appears to be true for BAME groups, who are seizing its power to help their children progress into successful adulthood, despite a context of wider racial disparities in society. Comparison of private tuition usage by ethnicity reveals that substantially higher proportions of children from BAME backgrounds have used this service at some point in their school career than the White majority (Asian 45.8\%; Black 44.1\%; Other 37.5\%; Mixed-Ethnicity 34.5\%; White

$21.7 \%) .{ }^{13}$ Moreover, significant differences between ethnicities are evident in tuition usage over the most recent year (Asian 23.5\%; Black 15.9\%; Mixed 15\%; Other 13\%; White 8.9\%). ${ }^{1415}$ 
This greater use of private tuition by BAME families has the potential to alter, rather than reproduce, the status quo along the axis of ethnicity (Baker et al 2014). Indeed, such statistics about tuition sit alongside evidence that the performance of these pupils, particularly the poorest, has been improving over recent years. Between 2006 and 2015, Chinese, Black, Asian and Mixed ethnic groups exceeded the overall rate of improvement for pupils achieving five good GCSEs (five at $A^{*}-C$, including English and maths). White British free school meal-entitled pupils (i.e. economically disadvantaged) are the poorest performing minor ethnic group at GCSE by the same measure, excluding travellers of Irish heritage and Gypsy/Roma (Kirby \& Cullinane 2016). The same is true in the most recent DfE data, using the measure of Attainment $8^{16}$ (DfE 2018). Several explanations have been posited for the improved performance of BAME pupils, including their concentration in urban areas where better schools are often located, differing levels of parental aspiration and, indeed, higher rates of private tutor usage (Kirby \& Cullinane 2016).

The poor deal some BAME groups receive from state education has also been offered as a trigger for tuition demand (Rollock et al 2015), but in considering this across England and Wales it is important to attend to diversity within the conceptual aggregation BAME. Previous research has suggested a substantial proportion of private tuition for Afro-Caribbean communities is undertaken via supplementary schools (Francis \& Hutchings 2013), which were founded in the 1960s to tackle racial biases in state schooling (Andrews 2013). This research finds that BAME children are more likely to receive longer group-tuition classes, possibly during weekends, while White pupils are more likely to receive individual tuition, which commonly lasts one hour, often on a school night. This is evidenced by significant ethnic differences in the tuition venue ${ }^{17}$ (with rates for tuition in a communal building being: Black 38.9\%; Asian 29\%; Mixed 27.3\%; Other 25\%; and White 19.8\%) and session length ${ }^{18}$ (e.g. greater proportions of BAME children receive tuition sessions lasting over an hour: BAME 38.5\%; White 15.7\%). The trend is more accentuated for Black pupils, suggesting that Afro-Caribbean supplementary schooling may indeed be significant (Andrews 2013).

The same pattern is also stronger amongst Asian than White groups, but an inability to disaggregate the category Asian in this secondary data set means it is not possible to examine whether this group tuition trend is driven, via migration or diasporic connections, by East Asian Confucian traditions and tutoring markets (Francis \& Archer 2005; Jheng 2015), or whether it emerges equally amongst Britons from South Asian backgrounds who utilise school education to cement success and secure social mobility (Gamsu 2018). Nevertheless, it is possible to state that there are no significant differences in how helpful diverse ethnic groups find tuition, despite differences in the balance of individual versus group instruction (Ireson 2004), suggesting that group tuition used by BAME pupils, contrary to that discussed in the previous section differentiated along the axis of class, is well-attuned to their needs. ${ }^{19}$

New insights into ethnic differentiation in the immediate motivations for tuition use are revealed through this research, and these have important implications for the forms of cultural 
capital that pupils develop through tuition (Bourdieu 2008) (see Table 2). ${ }^{20}$ Black children are most likely to receive tuition to help with school work in general, possibly to make-up for racial biases in mainstream education (Andrews 2013; Rollock et al 2015). Asian children report the highest levels of private tuition focused on success in specific GCSE examinations. In both instances, the focus is upon gaining educational credentials that will help children transition into post-16 education and the labour market. This picture is reinforced by significant ethnic differences in tuition in maths, English and the sciences. ${ }^{21}$ Asian and Black children receive above average rates of tuition in these core subjects, demonstrating a concerted effort by families to maximise attainment (Rollock et al 2015); conversely, White pupils have below average tuition rates in subjects crucial to educational transitions (Mixed and Other pupils' practices are varied). It is conspicuous that these differences emerge despite there being no significant variations in how well BAME and White students consider they are performing prior to tuition, suggesting that this will advance the position of BAME pupils. ${ }^{22}$

[Table 2 here]

However, greater BAME enthusiasm for tuition is not uniformly replicated for non-core curriculum subjects (e.g. foreign languages, musical instrument tuition). Notably, Asian children receive the least musical instrument tuition, a form of learning associated with the acquisition of embodied, rather than institutionalised, cultural capital (Hampshire \& Matthijsse 2010). This suggests that, for this group, the aim is to support focused academic achievement rather than create a rounded Renaissance child (Vincent and Ball 2007) through other 'criteria that count' (Gamsu, 2018: 1170). This insight into Black and Asian families' greater focus on core academic achievement, in comparison to their White counterparts, highlights tuition's potential to shape educational success in the context of wider racial disparities, and potentially the varied ways in which neoliberal logics in education are internalised and co-opted by different ethnic groups. Such insight now needs to be extended through qualitative research that facilitates analysis of the agency of BAME and White families, the cultural values they bring to education, as well as the extent to which tuition is viewed as a tool for reproducing privilege, securing social mobility and contesting discrimination.

\section{Supplementary education and the lessons from intersectional analysis}

The analysis presented so far exposes the power of marketised education to reinforce existing regional and class privilege, even while it is used to potentially promote progressive social change by challenging historical race-based educational inequalities. Exploration of the intersection between these patterns is essential. At a broader scale, variation along one axis of difference might simply be explained by the others (for example, regional patterns might simply reflect the class and ethnic constituency of the population). Regression analysis shows that this is not the case: questions about postcode lotteries, entrenched class inequality and the potential for BAME advancement all matter in the case of private tuition (see Table 3). This is evident as the first three 
steps of a binary regression analysis, centred on region, class and ethnicity, all make a significant contribution to the chi-square value of the model co-efficients (Step 1 Region $X^{2}(9)=99.770 p=.000$; Step 2 Class $X^{2}(2)=71.188 p=.000$; Step 3 Ethnicity $X^{2}(4)=83.436 p=.000$ ); the final step, which considers interactions, is also significant (Step 4 Interaction $\left.X^{2}(45)=62.963 p=.040\right) .{ }^{23}$ Moreover, the odds ratios indicate that the impact of region, class and ethnic differences on private tuition usage are roughly equal. In terms of region, the odds of children in the North West using tuition are $80 \%$ lower than for London-based pupils. The odds of low-FAS pupils using tuition are $80 \%$ less than for their high-FAS counterparts. Likewise, the odds of White pupils receiving tuition are $75 \%$ lower than for their Asian peers. Thus, private tuition usage is distinctly shaped by region, class and ethnicity, with each mattering to a similar extent.

\section{[Table 3 here]}

At the individual level, diverse axes of identity such as class, ethnicity and geographical community inevitably intersect in the lives of individuals (Gillborn 2015). In this case, an intersectional analysis of the impact of region, class and ethnicity in the lives of children reveals stark variations in tuition usage. For example, $77.8 \%$ of high-FAS, Asian Londoners report using private tuition, suggesting access is normalised for this group, compared with $0 \%$ of low-FAS, White pupils from the North West. These intersections underpin new formations of spatialised, classed and racialised privilege in England and Wales, with the most disadvantaged group in the tutoring 'arms race' being poor, White, Northern children, who also fare poorly in state education (House of Commons Education Committee 2014; Kirby 2016). Appreciation of this changing picture of disadvantage is important, but it is also crucial that we do not oversimplify it. For example, $93.3 \%$ of medium-FAS, Asian children in the North West also do not have access to tuition. This matters because it demonstrates that BAME families' ability to use private tuition to challenge race-based inequalities is fundamentally articulated through regional and classed inequalities (Gamsu 2018). Wealthier BAME groups located in the English capital can use this market opportunity to their advantage, but their BAME counterparts from less wealthy and regional backgrounds are unlikely to benefit from the growth of private tuition, in a process that produces new configurations of regional, class and racialised dis/advantage.

\section{Conclusion}

In the twenty-first century, geographers have charted transformations in educational landscapes as neoliberal restructuring has brought sweeping changes to policy and practice (Cohen and Lizotte 2015; Mills 2018; Nguyen et al 2017). Supplementary education, such as private tuition, which is delivered outside the boundaries of schooling yet is commonly designed to improve formal educational performance, is a significant omission from this picture. This paper draws on largescale quantitative research to address this lacuna and in so doing makes three key contributions to geographical knowledge. 
First, the paper broadens the definitions of what counts as education in geographic research, and meticulously traces the contours of this burgeoning educational market and its consequences for social reproduction. Making visible a market that has previously been hidden from both policy regulation and academic view (Bray 2017) is an important advance. The research demonstrates that the private tuition market in England and Wales is flourishing and researchers can no longer overlook a form of educational provision that reaches over one quarter of children in state secondary schools. This highly instrumental service - designed principally to help children gain access to academically high-performing schools and support their national exam performance - is considered useful by $93 \%$ of those who use it.

Focusing geographical attention on private tuition is crucial as the paper reveals the market is socio-spatially differentiated. Geography matters at the regional level as the English and Welsh private tuition market is spatially uneven, being most developed in London and least so in parts of Northern England, meaning that children now face a tuition postcode lottery that maps onto existing regional inequalities in state school funding (Clifton et al 2016). Furthermore, focused scrutiny demonstrates that the renaissance of a service once used principally by the gentry is highly classed, acting as a mode through which higher socio-economic groups can consolidate and perpetuate advantage, differentiating their children from others in highly competitive educational landscapes and labour markets marked by a surfeit of graduates (ONS 2017). This finding, though unsurprising, is socially significant, especially when combined with the more detailed assessment that shows that while some low-income families do make targeted use of private tuition to help children with examinations, their efforts to secure individual social mobility in the context of a broadly class regressive system are likely to be hampered by the lower quality of provision available to them.

Yet, while tuition perpetuates the regional and class status quo, its greater use by BAME groups facilitates, to an extent, minority ethnic advancement. It is one factor, amongst others, that contributes to marked recent improvements in BAME pupils' educational attainment in England and Wales (DfE 2018), with use at least partially motivated by the desire to circumnavigate wider racial biases (Rollock et al 2015), as part of broader strategies to ensure upward social mobility (Gamsu 2018). However, intersectional analysis (Gillborn 2015) reveals that the positive potential of tuition to rupture racial disadvantage by enhancing educational attainment is mediated through enduring regional and class differences. Wealthier BAME groups in the English heartlands (especially London) stand to benefit from this new market, but BAME groups from disadvantaged class or regional backgrounds are unlikely to share in the spoils, while white, Northern, working-class children now find themselves at the bottom of the pile (House of Commons Education Committee 2014).

Second, the paper advances conceptual debates about socio-spatial specificity in global neoliberal education policy (Brooks et al. 2012; Papanastasiou 2017) by directing attention to the ways the emergence of policy is shaped by market forces. In this instance, this renaissance of 
private tuition as a supplementary education service has its roots in the neoliberalisation of education, which has driven both the marketisation of schooling and the responsibilisation of families for educational success (Millar 2018; Whitty \& Wisby, 2016). In this marketplace, where parents are exhorted to exercise their 'moral agency' to choose a school for their child (Olmedo \& Wilkins 2016), and where they are held accountable for children's educational outcomes (DfE 2016), the parents and children who employ tuition to support access to, and performance within, education, are reconstituted as self-actualising neoliberal subjects (Raco 2009).

Crucially, the supplementary education market thus emerges in England and Wales as consecutive neoliberal education policies, a free market in private tuition, and the actions of responsibilised citizens, come together in practice. The conceptual lesson this teaches us is that not only must we attend to the particularities of neoliberal state strategies in particular time-places (Brooks et al. 2012), but also that we must consider how these policy directives intersect with contingent business forms and consumer behaviour to reshape the education landscapes in new, sometimes unintended, ways. Neoliberal education policy, this study shows, is not simply a matter for the government; instead, the political turn to business logics has strengthened market forces that, in terms of both supply and demand, now shape educational practices in ways that extend far beyond state control.

Finally, the study underscores the importance of avoiding the reductive supposition that the questionable politics underpinning neoliberal restructuring inevitably produces regressive outcomes (Mills \& McCreary 2013; Gallagher 2018). If we are to understand the nuances of social change, uniform, a priori judgements should make way for nuanced examinations that either firmly evidence injustices, or alternatively account for moments of hope in apparently bleak times. In this case, the detailed analysis of the progressive and regressive possibilities of private tuition has important implications for how we think about social mobility and social reproduction in neoliberal contexts. The neoliberal social imaginary posits education markets as a source of social mobility (Snee and Devine 2018). There is some evidence to support this supposition in supplementary education markets; for example, tuition may allow some BAME children to negotiate a wider landscape of racial injustice by enhancing their educational qualifications. This reconfiguration of educational inequality matters both to society and the individuals involved, and thus we should be alert to potentially progressive moments within neoliberal change (Mills \& McCreary 2013; Gallagher 2018). Nevertheless, the wider lesson of the study is that neoliberal education markets have limited capacity to fundamentally reshape social reproduction in positive ways (Snee and Devine 2018). Markets may reconfigure some aspects of educational inequality, but they also strongly reinforce others (here, especially in terms of class and region), in a process which subtly realigns axes of disadvantage, but does nothing to reduce overall levels of inequality (Gamsu 2018). In this instance, the marketisation of schooling, an unregulated tuition industry, and differentiated consumer action, combine to produce specific moments of rupture in patterns of inequality, through practices which offer the hope of social mobility for a limited few. At the same 
time, they contribute to the social reproduction of inequality through an educational landscape still shaped by enduring regimes of power.

\section{Acknowledgements}

We are extremely grateful to the Sutton Trust for granting access their data set and to Ipsos MORI for facilitating this. Many thanks to: three anonymous referees, John Harrison and Helena PimlottWilson for their insightful comments on earlier versions of this paper; Richard Buxton and Maggie Snowling for initial discussions regarding the data; and participants at the Third International Conference on Geographies of Education, The International Children's Day Workshop and The Tutors' Association Annual Conference for thought-provoking questions. Despite their assistance, any mistakes remain the authors' own.

\section{References}

Andrews K (2013) Resisting Racism: Race, Inequality and the Black Supplementary School Sovement. London: Trentham

Aurini J, Davies S and Dierkes J (2013) Out of the Shadows: The Global Intensification of Supplementary Education. Bingley: Emerald Books

Baker C, Dawson D, Thair T and Youngs R (2014) Longitudinal Study of Young People in England: Cohort 2, Wave 1. London: Department for Education

Bolton P (2017) Grammar School Statistics. London: House of Commons Library

Bourdieu P (2008) The forms of capital. In Biggart NW (ed) Readings in Economic Sociology (pp 280-91). Oxford: Blackwell

Bray M (2017) Schooling and its supplements: changing global patterns and implications for comparative education. Comparative Education Review 61:469-491

Bray M (2010) Researching shadow education: methodological challenges and directions. Asia Pacific Education Review 11:3-13

Bray M and Kobakhidze MN (2014) The global spread of shadow education. In. Napier DB (ed) Qualities of Education in a Globalised World (pp 185-200). Rotterdam: SensePublishers

Brenner N and Theodore N (2002) Cities and the geographies of "actually existing neoliberalism".

Antipode 34:349-79

Brooks R, Fuller A and Waters J (2012) Changing Spaces of Education: New Perspectives on the Nature of Learning. London: Routledge

Butler T, Hamnett C and Ramsden MJ (2013) Gentrification, Education and Exclusionary

Displacement in East London. International Journal of Urban and Regional Research 37:556-575

Chanfreau J, Tanner E, Callanan M, Laing K, Paylor J, Skipp A and Todd L (2015) Unequal Access to Out of School Activities (Briefing Paper 1). London: NatCen Social Research Cheng Y'E (2015) Biopolitical geographies of student life: private higher education and citizenship life-making in Singapore. Annals of the Association of American Geographers 105:1078-93 Clifton J, Round A and Raikes L (2016) Northern Schools: Putting Education at the Heart of the 
Northern Powerhouse. Manchester: Institute for Public Policy Research

Cohen D and Lizotte C (2015) Teaching the market: fostering consent to education markets in the United States. Environment and planning A 47: 1824-1841

Cohen DH (2013) The new boom in home tuition - if you can pay $£ 40$ an hour. The Guardian $25^{\text {th }}$ October (https://www.theguardian.com/education/2013/oct/25/new-boom-home-tuition)

Craig L, Powel, A and Smyth C (2014) Towards intensive parenting? Changes in the composition and determinants of mothers' and fathers' time with children 1992-2006. The British Journal of Sociology 65:555-579

Cribb J, Hood A, Joyce R and Norris Keiller A (2017) Living Standards, Poverty and Inequality in the UK: 2017. London: Institute for Fiscal Studies

Department for Education (DfE) (2016) Educational Excellence Everywhere. London: Her Majesty's Stationery Office

Department for Education (DfE) (2018) SFR01/2018: GCSE and equivalent results in England 2016/17 (Revised)

https://www.gov.uk/government/uploads/system/uploads/attachment data/file/676351/SFR

012018 National Characteristics tables.xlsx (last accessed 13 November 2018)

Department for Education and Employment (DfEE) (1997) Excellence in Schools. London: Her Majesty's Stationery Office

Doherty C and Dooley K (2018) Responsibilising parents: the nudge towards shadow tutoring. British Journal of Sociology of Education 39:551-566

Education Endowment Foundation (EEF) (2018) One to one tuition: technical appendix.

https://educationendowmentfoundation.org.uk/evidence-summaries/teaching-learningtoolkit/one-to-one-tuition/technical-appendix (last accessed 13 November 2018)

Farrales M (2017) Delayed, deferred and dropped out: geographies of Filipino-Canadian high school students. Children's Geographies 15:207-223

Francis B and Archer L (2005) British-Chinese pupils' and parents' constructions of the value of education. British Educational Research Journal 31:89-108

Francis B and Hutchings M (2013) Parent Power? Using Money and Information to Boost

Children's Chances of Educational Success. London: Sutton Trust

Frank A and Weck S (2018) Being Good Parents or Being Good Citizens: Dilemmas and Contradictions of Urban Families in Middle-Class Enclaves and Mixed Neighbourhoods in Germany. International Journal of Urban and Regional Research 42:20-35

Gallagher A (2018) The business of care: Marketization and the new geographies of childcare.

Progress in Human Geography 42:706-722

Gamsu S (2018) 'The "other” London effect: the diversification of London's suburban grammar schools and the rise of hyper-selective elite state schools'. The British Journal of Sociology 69:1155-1174

Gillborn D (2015) Intersectionality, critical race theory, and the primacy of racism: race, class, gender, and disability in education. Qualitative Inquiry 21:277-287

Gillborn D and Youdell D (2000) Rationing Education: Policy, Practice, Reform and Equity. 
Buckingham: Open University Press

Gillies V (2012) Family policy and the politics of parenting: from function to competence. In Richter

M and Andresen S (eds) The Politicization of Parenthood (pp 13-26). London: Springer Gordon P and Lawton D (1999) Royal Education: Past, Present and Future. London: Frank Cass Hall S (2015) Geographies of marketisation in English higher education: territorial and relational markets and the case of undergraduate student fees. Area 47: 451-458

Hamnett C and Butler T (2011) 'Geography matters': The role distance plays in reproducing educational inequality in East London. Transactions of the Institute of British Geographers 36:479-500

Hampshire K and Matthijsse M (2010) Can arts projects improve young people's wellbeing? A social capital approach. Social Science \& Medicine 71:708-716

Hays S (1996) The Cultural Contradictions of Motherhood. London: Yale University Press Higton J, Archer R, Dalby D, Robinson S, Birkin G, Stutz A, Smith R and Duckworth V (2017) Effective Practice in the Delivery and Teaching of English and Mathematics to 16-18 Year Olds. London: Department of Education

Holloway SL and Pimlott-Wilson H (2013) Parental involvement in children's learning: Mothers' fourth shift, social class, and the growth of state intervention in family life. The Canadian Geographer 57:327-336

House of Commons Education Committee (2014) Underachievement in Education by White Working Class Children. London: House of Commons

Ireson J (2004) Private tutoring: how prevalent and effective is it? London Review of Education 2:109-122

Ireson $\mathrm{J}$ and Rushforth K (2011) Private tutoring at transition points in the English education system: its nature, extent and purpose. Research Papers in Education 26:1-19

Jheng Y-J (2015) The influence of private tutoring on middle-class students' use of in-class time in formal schools in Taiwan. International Journal of Educational Development 40:1-8

Kirby P (2016) Shadow schooling: Private Tuition and Social Mobility in the UK. London: Sutton Trust

Kirby P and Cullinane C (2016) Class differences: Ethnicity and disadvantage. London: Sutton Trust

Lareau A (2002) Invisible inequality: social class and childrearing in black families and white families. American Sociological Review 67:747-776

Lawson J and Silver H (2007) A Social History of Education in England. Abingdon, Oxon: Routledge

Millar F (2018) The Best for My Child: Did the School Market Deliver? Woodbridge: John Catt Educational Limited

Mills Suzanne and McCreary T (2013) Negotiating neoliberal empowerment: Aboriginal people, educational restructuring, and academic labour in the North of British Columbia, Canada. Antipode 45:1298-1317

Mills Sarah and Kraftl P (2014) Informal Education, Childhood and Youth: Geographies, Histories, 
Practices. Basingstoke: Palgrave Macmillan

Mitchell K (2018) Making Workers: Radical Geographies of Education. London: Pluto Press

Nguyen N, Cohen D and Huff A (2017) Catching the bus: a call for critical geographies of education. Geography Compass 11 (doi: 10.1111/gec3.12323)

Office for National Statistics (ONS) (2017) Graduates in the UK Labour Market. London: Office for National Statistics

Olmedo A and Wilkins A (2016) Governing through parents: a genealogical enquiry of education policy and the construction of neoliberal subjectivities in England. Discourse: Studies in the Cultural Politics of Education 38:573-589

Orford S (2018) The capitalisation of school choice into property prices: A case study of grammar and all ability state schools in Buckinghamshire, UK. Geoforum 97:231-241

Papanastasiou N (2017) The practice of scalecraft: scale, policy and the politics of the market in England's academy schools. Environment and Planning A 49:1060-1079

Pearce S, Power S and Taylor C (2018) Private tutoring in Wales: patterns of private investment and public provision. Research Papers in Education 33:113-126

Peters M (2012) Neoliberalism, education and the crisis of Western capitalism. Policy Futures in Education 10:134-141

Pimlott-Wilson $\mathrm{H}$ (2017) Individualising the future: the emotional geographies of neoliberal governance in young people's aspirations. Area 49:288-295

Pimlott-Wilson $\mathrm{H}$ and Coates $\mathrm{J}$ (2019) Rethinking learning? Challenging and accommodating neoliberal educational agenda in the integration of Forest School into mainstream educational settings. The Geographical Journal (EarlyView: https://doi.org/10.1111/geoj.12302)

Pratt N (2016) Neoliberalism and the (internal) marketisation of primary school assessment in England. British Educational Research Journal 42:890-905

Raco M (2009) From expectations to aspirations: state modernisation, urban policy, and the existential politics of welfare in the UK. Political Geography 28:436-44

Richter M and Andresen S (2012) The politicization of parenthood: shifting private and public responsibilities in education and child rearing. In Richter M and Andresen S (eds) The Politicization of Parenthood (pp 1-10). London: Springer

Rivera L (2015) Pedigree: How Elite Students Get Elite Jobs. Princeton, NJ: Princeton University Press

Rollock N, Gillborn D, Vincent C and Ball SJ (2015) The Colour of Class: The Educational Strategies of the Black Middle Classes. London: Routledge

Silova I (2010) Private tutoring in Eastern Europe and Central Asia: policy choices and implications. Compare: A Journal of Comparative and International Education 40:327-344

Snee $\mathrm{H}$ and Devine $\mathrm{F}$ (2018) Fair chances and hard work? Families making sense of inequality and opportunity in 21st-century Britain. The British Journal of Sociology 69:1134-1154

Song K.-O, Par, H.-J and Sang K-A (2013) A cross-national analysis of the student- and schoollevel factors affecting the demand for private tutoring. Asia Pacific Education Review 
$14: 125-139$

Sutton Trust (2018) About us. https://www.suttontrust.com/about-us/ (last accessed 13 November 2018)

Tanner E, Day N, Tennant R, Turczuk O, Ireson J, Rushforth K and Smith K (2009) Private Tuition in England. London: NatCen

Vincent C and Ball SJ (2007) "Making up" the middle-class child: families, activities and class dispositions. Sociology 41:1061-1077

Vingaard Johansen U, Knudsen FB, Kristofferson CE, Rasmussen JS, Steffen ES and Sund KJ (2017) Political discourse on higher education in Denmark: From enlightened citizen to homo economicus. Studies in Higher Education 42:264-277

Whitty $G$ and Wisby $E$ (2016) Education in England - a testbed for network governance? Oxford Review of Education 42:316-329

Yoon E-S, Lubienski C and Lee J (2018) The geography of school choice in a city with growing inequality: the case of Vancouver. Journal of Education Policy 33:279-298 
Table 1: Regional variations in percentage of pupils who have ever used private tuition

\begin{tabular}{|c|c|c|}
\hline & 2005 & 2016 \\
\hline England and Wales ${ }^{a}$ & 18.3 & 26.2 \\
\hline London ${ }^{b}$ & 35.5 & 43.8 \\
\hline Wales $^{c}$ & 14.8 & 28.3 \\
\hline East of England ${ }^{d}$ & 14.2 & 28.2 \\
\hline South East ${ }^{\mathrm{e}}$ & 19.2 & 27.9 \\
\hline East Midlands ${ }^{\dagger}$ & 12.4 & 27.5 \\
\hline North East ${ }^{g}$ & 15.3 & 23.6 \\
\hline West Midlands ${ }^{h}$ & 13.7 & 23.3 \\
\hline South West ${ }^{\mathrm{i}}$ & 19.9 & 23.1 \\
\hline Yorkshire and Humberside & 13.3 & 16.4 \\
\hline North West (including Merseyside) ${ }^{\mathrm{k}}$ & 15.9 & 13.5 \\
\hline
\end{tabular}

Table 2: Ethnic variations in percentage pupils who have received private tuition for these reasons/subjects

\begin{tabular}{lllllll}
\hline & White & Black & Asian & Mixed & Other & Mean \\
\hline General school work & 43.2 & 71.4 & 51.5 & 47.2 & 100 & 48.5 \\
Specific GCSEs & 34.3 & 37.1 & 55.4 & 43.2 & 33.3 & 38.6 \\
Maths & 64.8 & 83.9 & 84.2 & 52.6 & 88.9 & 69.5 \\
English & 47.3 & 56.5 & 63.4 & 55.3 & 33.3 & 51.1 \\
Sciences & 14.6 & 44.3 & 41.6 & 15.8 & 37.5 & 22.4 \\
Instrument & 22.5 & 24.6 & 11.9 & 42.1 & 12.5 & 22.1 \\
Foreign Language & 10.4 & 4.9 & 8.9 & 13.2 & 0.0 & 9.6
\end{tabular}

Note: Shaded figures indicate significant ethnic differences in receipt of private tuition for that reason/subject. ${ }^{1718}$ 
Table 3: Binomial logistic regression model exploring impact of region, class and ethnicity on private tuition usage

\begin{tabular}{|c|c|c|c|c|}
\hline \multirow[t]{2}{*}{ Step } & \multirow[t]{2}{*}{ Variable } & \multirow[t]{2}{*}{$\operatorname{Exp}(B)$} & \multicolumn{2}{|c|}{$\begin{array}{c}\text { 95\% Confidence Interval for } \\
\operatorname{EXP(B)}\end{array}$} \\
\hline & & & Lower & Upper \\
\hline \multirow[t]{10}{*}{ Step 1} & London & 1.00 & & \\
\hline & East of England & .506 & .360 & .713 \\
\hline & East Midlands & .458 & .313 & .668 \\
\hline & North East & .398 & .244 & .651 \\
\hline & North West & .191 & .128 & .285 \\
\hline & South East & .490 & .356 & .673 \\
\hline & South West & .348 & .235 & .515 \\
\hline & Wales & .505 & .323 & .791 \\
\hline & West Midlands & .376 & .262 & .541 \\
\hline & $\begin{array}{l}\text { Yorkshire \& } \\
\text { Humber }\end{array}$ & .242 & .160 & .365 \\
\hline \multirow[t]{13}{*}{ Step 2} & London & 1.00 & & \\
\hline & East of England & .372 & .260 & .533 \\
\hline & East Midlands & .323 & .218 & .480 \\
\hline & North East & .281 & .169 & .465 \\
\hline & North West & .146 & .096 & .220 \\
\hline & South East & .381 & .273 & .531 \\
\hline & South West & .261 & .174 & .392 \\
\hline & Wales & .409 & .258 & .648 \\
\hline & West Midlands & .288 & .197 & .420 \\
\hline & $\begin{array}{l}\text { Yorkshire \& } \\
\text { Humber }\end{array}$ & .192 & .125 & .293 \\
\hline & High-FAS & 1.00 & & \\
\hline & Medium-FAS & .477 & .382 & .596 \\
\hline & Low-FAS & .281 & .184 & .427 \\
\hline \multirow[t]{18}{*}{ Step 3} & London & 1.00 & & \\
\hline & East of England & .516 & .352 & .757 \\
\hline & East Midlands & .468 & .310 & .707 \\
\hline & North East & .442 & .261 & .749 \\
\hline & North West & .194 & .126 & .299 \\
\hline & South East & .564 & .395 & .805 \\
\hline & South West & .388 & .253 & .594 \\
\hline & Wales & .685 & .421 & 1.116 \\
\hline & West Midlands & .369 & .248 & .548 \\
\hline & $\begin{array}{l}\text { Yorkshire \& } \\
\text { Humber }\end{array}$ & 289 & .184 & .452 \\
\hline & High-FAS & 1.00 & & \\
\hline & Medium-FAS & .405 & .321 & .511 \\
\hline & Low-FAS & .197 & .126 & .307 \\
\hline & Asian & 1.00 & & \\
\hline & Black & .714 & .451 & 1.131 \\
\hline & White & .255 & .185 & .351 \\
\hline & Mixed & .509 & .306 & .846 \\
\hline & Other & .532 & .206 & 1.369 \\
\hline
\end{tabular}


${ }^{1} X^{2}(1)=45.125 ; p=.000$.

${ }^{2} \mathrm{~N} \neq 100$ (respondents may select $>1$ option).

${ }^{3}$ Intra-national variation 2016: $X^{2}(9)=97.278 ; p=.000$.

${ }^{4}$ Nation-Regional comparisons 2016 (see Table 3): $a-b: X^{2}(1)=46.817 ; p=.000$; $a-c: X^{2}(1)=.297 ; p=.586$; $a-$ $\mathrm{d}: \mathrm{X}^{2}(1)=.526 ; p=.468 ; \mathrm{a}-\mathrm{e}: \mathrm{X}^{2}(1)=.460 ; p=.497 ; \mathrm{a}-f: \mathrm{X}^{2}(1)=.185 ; \mathrm{p}=.667 ; \mathrm{a}-\mathrm{g}: \mathrm{X}^{2}(1)=.349 ; p=.554 ; \mathrm{a}-\mathrm{h}$ : $X^{2}(1)=.959 ; p=.327 ; a-i: X^{2}(1)=1.007 ; p=.316 ; a-j: X^{2}(1)=10.933 ; p=.001 ; a-k: X^{2}(1)=23.328 ; p=.000$.

${ }^{5}$ Nation-Regional comparisons 2005 (see Table 3): $a-b: X^{2}(1)=58.087 ; p=.000 ; a-c: X^{2}(1)=1.273 ; p=.259$; $a-$ $\mathrm{d}: \mathrm{X}^{2}(1)=2.833 ; p=.092 ; a-e X^{2}(1)=0.148 ; p=.701 ; a-f: X^{2}(1)=4.738 ; p=.030 ; a-g: X^{2}(1)=0.789 ; p=.374 ; a-$ $h: X^{2}(1)=3.786 ; p=.052 ; a-i: X^{2}(1)=0.367 ; p=.544 ; a-j: X^{2}(1)=4.212 ; p=.040 ; a-k: X^{2}(1)=1.295 ; p=.255$.

6 2005-2016 intra-region change (see Table 3): $a=X^{2}(1)=45.125 ; p=.000 ; b=X^{2}(1)=5.040 ; p=.025$; $c=X^{2}(1)=7.924 ; p=.005 ; d=X^{2}(1)=15.976 ; p=.000 ; e=X^{2}(1)=7.083 ; p=.008 ; f=X^{2}(1)=15.193 ; p=.000 ;$ $g=X^{2}(1)=2.712 ; p=.100 ; h=X^{2}(1)=8.546 ; p=.003 ; i=X^{2}(1)=0.684 ; p=.408 ; j=X^{2}(1)=0.920 ; p=.338$; $k=X^{2}(1)=0.760 ; p=.383$.

${ }^{7} X^{2}(2)=42.525 ; p=.000$

${ }^{8} X^{2}(2)=12.945 ; p=.002$.

${ }^{9} X^{2}(6)=17.076 ; p=.009$

${ }^{10} X^{2}(6)=19.588 ; p=.003$

${ }^{11} \mathrm{X}^{2}(2)=6.471 ; p=.039$ (Excludes other/varied)

$12 X^{2}(1)=8.116 ; p=.017$

${ }^{13} X^{2}(4)=95.634 ; p=.000$

${ }^{14} X^{2}(4)=50.330 ; p=.000$.

${ }^{15}$ By contrast, although gender differences do matter in educational attainment (DfE 2018), there are no significant differences in boys' and girls' tuition use. ( $\left.X^{2}(1)=3.679 ; p=.055\right)$.

${ }^{16}$ Attainment 8 measures a pupil's average attainment across 8 subjects at age 16, placing greater weight on Maths and English, whilst also prioritising traditional academic subjects (e.g. sciences, history/geography, languages).

$17 \mathrm{X}^{2}(4)=11.468 ; p=.022$ (Excludes other/varied).

${ }^{18} X^{2}(3)=42.928 ; p=.000$ (White/BAME).

${ }^{19} X^{2}(1)=0.031 ; p=.860$ (White/BAME).

20 General school work: $X^{2}(4)=27.702 ; p=.000 ;$ Specific GCSE: $X^{2}(4)=15.761 ; p=.003 .$.

${ }^{21}$ Maths: $X^{2}(4)=27.236 ; p=.000 ;$ English $: X^{2}(4)=10.555 ; p=.032 ;$ Sciences $: X^{2}(4)=54.084 ; p=.000$; Instrument: $X^{2}(4)=15.671 ; p=.003$. Foreign Language: $X^{2}(1)=.794 ; p=.373$ (White/BAME).

${ }^{22} \mathrm{X}^{2}(3)=3.791 ; \mathrm{p}=.285$ (White/BAME).

${ }^{23}$ Degrees of freedom reduced due to redundancies. To avoid over interpreting small samples, odds ratios for interactions are excluded from further analysis. 